\title{
Effect of freezing on the conservation of the biological activity of organic solid wastes
}

Michele Pognani, Raquel Barrena, Xavier Font and Antoni Sánchez*

Composting Research Group, Department of Chemical Engineering, Universitat Autònoma de Barcelona, Bellaterra (Cerdanyola del Vallès, 08193-Barcelona, Spain).

* Corresponding author: Dr. Antoni Sánchez; E-mail: antoni.sanchez@ uab.cat; Tel.: (34) 93 5811019; Fax: (34) 935812013.

\begin{abstract}
To assess the effect of freezing on the indigenous biological activity of an organic waste, five types of organic wastes (Raw Sludge [RS], Municipal Solid Waste [MSW], partially processed Municipal Solid Waste [MSWpp], Digested Sludge [DS] and composted Organic Fraction of Municipal Solid Waste [OFMSWc]) were frozen and stored during different times to identify if the interruption of the native biological activity was recovered. Respiration indices ( $\mathrm{DRI}_{24 \mathrm{~h}}$ and $\mathrm{AT}_{4}$ ) were used to determine the biological activity expressed as oxygen consumption. ANOVA analysis was used to compare the results. Respiration indices of RS, DS, MSWpp and OFMSWc were not affected by freezing storage during one year. Contrarily, respiration indices of MSW samples were statistically different after 52 and 20 weeks of freezing storage ( $\mathrm{DRI}_{24 \mathrm{~h}}$ and $\mathrm{AT}_{4}$, respectively). Regarding the lag phase and the time to reach maximum respiration activity, frozen samples induced a significant change in the organic samples analyzed except for OFMSWc.
\end{abstract}

Keywords: Stability; Composting; Organic solid sample; Freezing; Respirometry.

Pre-print of: Pognani, M. et al. "Effect of freezing on the conservation of the biological activity of organic solid wastes" in Bioresource technology (Ed. Elsevier), vol. 104 (Jan. 2012), p. 832-836. The final version is available at DOI 10.1018/j.biortech.2011.11.097 


\section{Introduction}

Ideally, organic samples should be immediately analyzed after sample collection. However, it is often desirable or necessary to store them before processing because of logistic constraints associated with the time duration of some biological tests or the sampling in remote locations. Sample storage requires the interruption of the biological activity avoiding the modification of the sample characteristics. Cooling between 4 to $0{ }^{\circ} \mathrm{C}$ (for few days) and freezing at $-18^{\circ} \mathrm{C}$ are the common preservation techniques for organic samples that cannot be analyzed at the collection moment (Wissmar et al., 1997; Mitchell and Lamberti, 2005).

To preserve the characteristics of the sample in further biological tests, the interruption of the native microbial activity obtained by freezing should be reversible. It is known that when bacteria are frozen and then thawed, their survival is dependent on many parameters such as cooling and warming rates and holding temperature (Gao et al., 2006). As a result of water freezing, some damage can be expected from several causes such as extracellular ice formation, intracellular ice formation (Thomashow, 1998), concentration of extracellular solutes or concentration of intracellular solute and low temperature (El-Kest and Marth, 1992; Lund, 2000). In extreme cases, the damage caused becomes irreparable and the cell succumbs (Archer, 2004). Moreover, the process of thawing may exert more damage as ice crystals grow (El-Kest and Marth, 1992).

However, this could lead to a false conclusion related to microorganisms' death, since the damaged microorganisms can become fully viable again (Archer, 2004). As stated by Lund (2000), gram negative bacteria are more susceptible to freezing than gram positive and the microbial growth stage is also a factor that can affect the cell viability during a freezing process (Foschino, 2002). To have consistent values of biological activity, Fellman et al. (2008) reported that is important to establish protocols for preserving samples to ensure their 
integrity. However, to our knowledge, the effect of freezing storage on complex organic solid waste samples still has not been determined.

In some cases, the need of sample storage occurs when a waste treatment facility is subjected to a massive sampling process to study its efficiency (Ponsá et al., 2010; Pognani et al., 2010). Under this situation, a large number of organic samples is collected. In organic solid waste samples, the effect of a large period of freezing can be determined by measuring the microbial activity of the sample before and after the freezing storage. This microbial activity can be determined by using respiration index tests such as the dynamic respiration index (DRI) or the cumulative oxygen consumption (AT) (Ponsa et al., 2010).

The objective of this study was to determine the changes in the biological activity measured in terms of respiration activity of five types of organic wastes that were frozen and thawed during different periods of time. A maximum freezing storage time for the organic samples was determined. Results were analyzed by respiration indices. Also, the duration of the lag phase and the time at which the maximum oxygen consumption occurs $\left(\mathrm{H}_{\max }\right)$ were also compared.

\section{Material and methods}

\subsection{Organic samples}

Five different types of organic wastes were selected in terms of their biodegradability estimated as biological activity: highly biodegradable samples (respiration activity higher than $5 \mathrm{~g} \mathrm{O}_{2} \mathrm{~kg}^{-1} \mathrm{TS} \mathrm{h}^{-1}$ ); moderately biodegradable samples (respiration activity within 2 to $5 \mathrm{~g} \mathrm{O}_{2}$

$\mathrm{kg}^{-1} \mathrm{TS} \mathrm{h}^{-1}$ ) and low biodegradability samples (respiration activity lower than $2 \mathrm{~g} \mathrm{O}_{2} \mathrm{~kg}^{-1} \mathrm{TS}$

$\mathrm{h}^{-1}$ ) (Ponsa et al., 2010). They were collected from full-scale waste treatment plants and wastewater treatment plants located in the province of Barcelona. Their main characteristics are shown in Table 1. 


\subsection{Experimental procedure}

Analytical methods were carried out on a representative sample (approximately $20 \mathrm{~kg}$ ) obtained by mixing four sub-samples $(5 \mathrm{~kg}$ each) taken from different points of the organic wastes. MSW sample was ground to $15-20 \mathrm{~mm}$ particle size to reduce the size of the original materials. Waste samples were stored in plastic bags (1 liter of volume) and frozen using a commercial freezer at $-18^{\circ} \mathrm{C}$ within four hours after sampling. One bag of each sample was stored at $4{ }^{\circ} \mathrm{C}$ and analyzed within two days corresponding to time 0 (fresh sample). These samples were used to carry out the entire set of analytical tests: $\mathrm{pH}$, Electrical Conductivity (EC), Total Solid (TS), Volatile Solids (VS), ammonia $\left(\mathrm{N}_{-} \mathrm{NH}_{3}\right)$ and total Kjeldahl nitrogen (TKN), which were determined according to the standard procedures recommended by the Test Methods for the Examination of Composting and Compost (TMECC) (US Department of Agriculture, 2001). $\mathrm{DRI}_{24 \mathrm{~h}}, \mathrm{AT}_{4}$, lag phase and $\mathrm{H}_{\max }$ were measured for each sample at different freezing time storage until reaching one year $(0,1,2,3,7,10,13,16,20,28,36,44$ and 52 weeks). Every ten weeks pH, CE, TS and VS tests were also measured. Before each analysis, samples were thawed during 12 hours at room temperature. All tests were run in triplicate and the results are presented as the average value followed by the standard deviation.

\subsection{Respiration tests}

The procedure used in this study for the determination and calculation of the dynamic respiration index $\left(\mathrm{DRI}_{24 \mathrm{~h}}\right)$ and the cumulative respiration activity after four days $\left(\mathrm{AT}_{4}\right)$, lag phase and $H_{\max }$ was based on previous works by Adani et al. (2004), Barrena et al. (2005) and Ponsá et al. (2010).

\subsection{Statistical analysis}


Respirometric assays were performed in triplicate. Average and standard deviation values from biological tests were calculated according to standard procedures and the results were analyzed by the ANOVA test. Tukey test was used to compare mean values and to assess the significance of the differences between mean values. All statistical analyses were carried out using the SPSS statistical software version 15.0 (SPSS, Chicago, IL) and an alpha value of 0.01 was selected for each statistical comparison.

\section{Results and discussion}

Table 1 shows the chemical characterization of the organic samples before the freezing process (fresh samples). TS, VS, pH and EC were also analyzed for each sample after thawing (each ten weeks). The obtained results on these parameters reported no statistically differences from the results obtained with fresh samples.

In order to assess the effect of freezing and freezing duration on the biological activity, the following parameters were measured: $\mathrm{DRI}_{24 \mathrm{~h}}, \mathrm{AT}_{4}$, lag phase (in hours) from time zero (beginning of the test) to the time when the oxygen uptake rate reaches at least $25 \%$ of the maximum uptake rate and this time (in hours) and the time between the end of the lag phase and the maximum oxygen consumption $\left(\mathrm{H}_{\max }\right)$.

The ANOVA analysis of $\mathrm{DRI}_{24 \mathrm{~h}}$ and $\mathrm{AT}_{4}$ values for $\mathrm{RS}$ did not show any significant statistical difference between the values obtained for each thawed sample. However, it was observed that the lag phase duration increased as the freezing time increased. Indeed, the ANOVA analysis grouped the lag phase duration in six classes. As example, Table 2 shows the ANOVA classification for RS lag phase results and Table 3 summarizes the effects of freezing for each studied parameter. ANOVA results shown in Table 2 highlighted that the fresh RS sample was statistical different from the samples that were subjected to a freezing process: fresh RS sample was classified alone (class 1), samples thawed at 1, 2, 3, 7, 13 and 16 weeks were grouped in the same class (class 2) and all the rest (except 1-week sample) 
were included in a third class. The sample thawed at 52 weeks was classified, together with the samples thawed at 28 weeks, in the class 6 and the other two class groups (4 and 5) were formed by samples present in the other groups. Regarding $\mathrm{H}_{\max }$, ANOVA analysis indicated the presence of four classes being fresh RS classified alone and the other samples classified in the remaining classes without showing a previously expected temporal order. RS samples showed a positive $\mathrm{DRI}_{24 \mathrm{~h}}$ correlation (Figure 1a) but ANOVA analysis reported that these differences were not statistically significant for this parameter and $\mathrm{AT}_{4}$ (Figure 1b). Figure 1d shows a negative correlation between the time of freezing and $\mathrm{H}_{\max }$ just after freezing but afterwards this trend is not observed. It can be hypothesized that the RS sample is mainly composed by active and viable microorganisms and the negative effect of freezing storage could be compensated by the high capacity that have this kind of samples to recover its normal microbial activity (Barrena et al., 2011). Unfortunately, there are no similar reports in literature to compare these results. Nevertheless, ANOVA analysis demonstrated that the freezing process changed the length of lag phase and $\mathrm{H}_{\max }$ from the first week of freezing storage.

ANOVA analysis of $\mathrm{DRI}_{24 \mathrm{~h}}$ values of MSW samples classified the results in two different classes. Fresh sample and 1-week frozen sample were classified in the same class, whereas the 52-weeks frozen sample was classified alone and all the other samples were included in the previous two classes. Fresh and 1-week samples were statistically different from the 52-weeks frozen sample indicating that a freezing period of 52 weeks should not be exceeded (Table 3). DRI $24 \mathrm{~h}$ evolution of MSW sample (Figure 1a) showed a negative trend during the storage time, which was confirmed by the ANOVA analysis, which confirmed that after 52 weeks of freezing storage, there was a significant difference. Regarding $\mathrm{AT}_{4}$ values four classes were obtained. Samples from fresh to 36 weeks (excluding 28 weeks) belonged to the same class. Considering that many values were classified in the second and third class and 
that from 28 to 52 weeks $\mathrm{AT}_{4}$ values were included in the same class, a limit of 20 weeks of frozen storage could be established to ensure the reliability of the $\mathrm{AT}_{4}$ test (Table 3). Lag phase ANOVA analysis showed a high dispersion (eight classes were generated) but a relatively expected temporal classification was observed. First class grouped fresh, 1, 2 and 3 weeks of frozen storage. The other classes included two or three values until 52 weeks of freezing. It was observed that from 3 weeks of freezing storage the lag phase length significantly increased (10\% every week) (Figure 1c). $\mathrm{H}_{\max }$ ANOVA analysis showed a positive trend similar than the lag phase (Figure 1d). Three classes were reported and from 16 weeks of frozen storage the values increased significantly (4\% every week).

Comparing the respiration results obtained with the fresh MSW sample with the 52weeks frozen MSW sample (data not shown), it was evident that the differences between both evolutions of oxygen consumption confirmed the results obtained by the ANOVA analysis. The change of all the trends of the respiration parameters could be caused by the necessity of the microorganisms to recreate and repopulate with new communities the organic matter due to the negative effects on their viability caused by freezing storage. Typically MSW, OFMSW and other similar kinds of organic samples have a moderate to high amount of rapidly biodegradable organic matter (Ponsá et al., 2011), which probably means that the bacterial communities that colonize these samples should be in the exponential phase of their growth. Lund (2000) and Foschino (2002) demonstrated that bacteria cells in the exponential phase of growth were more susceptible to freezing than when they were in the stationary phase. This could explain why freezing these samples could damage the bacterial cells of the sample and slow down the recuperation of the biological activity.

Regarding $\mathrm{DRI}_{24 \mathrm{~h}}$ and $\mathrm{AT}_{4}$ of MSWpp samples, the ANOVA analysis did not show statistical differences. In relation to the lag phase, ANOVA analysis identified six classes and 10 weeks could be established as the maximum freezing time (Table 3). Regarding $\mathrm{H}_{\max }$, 
ANOVA analysis reflected four different classes but any temporal evolution could be determined. Fresh sample was included in the first and the second class and the 52-weeks frozen sample was included in the third and fourth class indicating a possible difference between fresh and frozen samples. A 28 weeks of maximum freezing storage time is proposed (Table 3). This behavior could be explained assuming that, as reported in Archer (2004), fungi and bacteria spores can survive to the thermophilic phase reached during the first weeks of composting process but thermophilic bacteria were in its active phase of growth and, in consequence, very sensible to freezing conditions. Also Lund (2000) and Archer (2004) reported that freezing temperatures could damage bacterial cells in a cumulative way that ended up in cells' death.

ANOVA analysis of respiration indices ( $\mathrm{DRI}_{24 \mathrm{~h}}$ and $\mathrm{AT}_{4}$ ) of DS samples did not show any statistical difference. DS lag phase identified three classes where fresh sample was placed alone in the first class. The other samples were shared between the second and the third class. Freezing storage significantly changed the lag phase length from the fresh sample (Table 3). Regarding $\mathrm{H}_{\max }$, ANOVA analysis identified two classes but no temporal trend could be determined due to the high dispersion of the results. Also, in DS samples organic matter was mainly composed by microorganisms that demonstrated not to be affected by freezing storage and to become fully viable after thawing.

Due to the high stability of the OFMSWc samples, the results of respiration indices $\left(\mathrm{DRI}_{24 \mathrm{~h}}\right.$ an $\left.\mathrm{AT}_{4}\right)$ obtained during the 52 weeks of assay showed little differences (Figure 1). ANOVA analysis confirmed that the differences were not statistically significant. ANOVA analysis of the lag phase and $\mathrm{H}_{\max }$ determined a large number of classes (eight and four respectively) but no temporal trend could be determined. Ryckeboer et al. (2003) reported that fungi, yeast and Streptomyces can survive the heat peak and freezing temperature as spores or 
being re-inoculated (Actinomicetes spp) in the compost from the environment during its storage.

To the authors' knowledge, this is the first work where a systematic study about the effects of freezing on the biological activity is presented for organic wastes in different stages of stabilization. Respiration assays were successfully used to determine and evaluate the activity of microbial communities after freezing. The results presented can be of high interest for the research on organic wastes, since the freezing times recommended to maintain the biological activity have been estimated for several wastes that are typically treated using biological technologies.

\section{Conclusions}

In general, it can be stated that freezing is a suitable technique to preserve organic solid waste samples without compromising the native vitality of microbial communities when the samples are thawed in order to perform the biological assays. It is normally assumed that freezing is the most adequate technique but, to the authors' knowledge, no systematic study has been published. Using respiration assays, the suitability of this technique for several organic wastes has been demonstrated and the times recommended for freezing the samples without changing the biological activity of the materials have been estimated.

\section{Acknowledgments}

Financial support was provided by the Spanish Ministerio de Educación y Ciencia (Project CTM2009-14073-C02-01). Michele Pognani has a pre-doctoral scholarship from the Spanish Ministerio de Ciencia e Innovación (Ref. BES-2007-17634). Raquel Barrena was supported by Juan de la Cierva post-doctoral contract from the Spanish Ministerio de Ciencia e Innovación (Ref. JCI-2008-1989). 


\section{References}

Archer, D.L., 2004. Freezing: an underutilized food safety technology? Review article. Int. J. Food Microbiol. 90, 127-138.

Adani, F., Confalonieri, R., Tambone, F., 2004. Dynamic respiration index as a descriptor of the biological stability of organic wastes. J. Environ. Qual. 33, 1866-1876.

Barrena, R., Vázquez, F., Gordillo, M.A., Gea, T., Sánchez, A., 2005. Respirometric assays at fixed and process temperature to monitor composting process. Bioresource Technol. 96, 1153-1159.

Barrena, R., Turet, J., Busquets, A., Farrés, M., Font, X. Sánchez, A., 2011. Respirometric screening of several types of manure and mixtures intended for composting. Bioresource Technol. 102, 1367-1377.

El-Kest, S.E., Marth, E.H., 1992. Freezing of Listeria monocytogenes and other microorganisms: a review. J. Food Protect. 55, 639-648.

Fellman, J.B., D’Amore, V.D., Hood, E., 2008. An evaluation of freezing as a preservation technique for analyzing dissolved organic C, N and P in surface water samples. Sci. Total Environ. 392, 305-312.

Foschino, R., 2002. Freezing injury of Escherichia coli during the production of ice cream. Ann. Microbiol. 52, 39-46.

Gao, W., Smith, D.W., Li, Y., 2006. Natural freezing as a wastewater treatment method: $E$. coli inactivation capacity. Water Res. 40, 2321-2326.

Lund, B.M., 2000. Freezing. In: Lund, B.M., Baird Parker, T.C., Gould, G.W. (Eds.), The Microbiological Safety and Quality of Food, vol. I. Aspen Publishers, Gaithersburg, MD, p. 122-145. 
Mitchell, N.L., Lamberti, G.A., 2005. Responses in dissolved nutrients and epilithon abundance to spawning salmon in southeast Alaska stream. Limnol. Oceanogr. 50, 217227.

Pognani, M., Barrena, R., Font, X., Scaglia, B., Adani, F., Sánchez, A., 2010. Monitoring the organic matter properties in a combined anaerobic/aerobic full-scale municipal sourceselected waste treatment plant. Bioresource Technol. 101, 6873-6877.

Ponsá, S., Gea, T., Sánchez, A., 2010. Different indices to express biodegradability in organic solid wastes. J. Environ. Qual. 39, 706-712.

Ponsá, S., Puyuelo, B., Gea, T., Sánchez, A., 2011. Modelling the aerobic degradation of organic wastes based on slowly and rapidly degradable fractions. Waste Manage. 31, $1472-1479$.

Ryckeboer, J., Mergaert, J., Coosemans, J., Deprins, K., Swings, J., 2003. Microbial aspects of biowaste during composting in a monitored compost bin. J. Appl. Microbiol. 94, 127137.

The U.S. Department of Agriculture and The U.S. Composting Council, 2001. Test Methods for the Examination of Composting and Compost. Edaphos Int., Houston, USA.

Thomashow, M.F., 1998. Role of cold-responsive genes in plant freezing tolerance. Plant Physiol. 118, 1-8.

Wissmar, R.C., Swanston, D.N., Bryant, M., Mcgee, K., 1997. Factors influencing stream chemistry in catchments on Prince of Wales Island, Alaska. Fresh Biol. 38, 301-314. 
Tables:

Table 1: Chemical characterization of the raw organic waste samples.

RS: raw sludge; MSW: municipal solid waste; MSWpp: municipal solid waste partially processed; DS: digested sludge; OFMSWc: composted organic fraction of municipal solid waste; EC: electrical conductivity; TS: total solids; VS: volatile solids; TKN: total Kjeldahl nitrogen; n.d.: not detected; ww: wet weight.

\begin{tabular}{ccccccccc}
\hline Sample & $\mathrm{pH}$ & $\begin{array}{c}\mathrm{EC} \\
\left(\mathrm{mS} \mathrm{cm}^{-1}\right)\end{array}$ & $\begin{array}{c}\mathrm{TS} \\
\left(\mathrm{g} \mathrm{kg}^{-1} \mathrm{ww}\right)\end{array}$ & $\begin{array}{c}\mathrm{VS} \\
\left(\mathrm{g} \mathrm{kg}^{-1} \mathrm{TS}\right)\end{array}$ & $\begin{array}{c}\left.\mathrm{N}_{\left(\mathrm{g} \mathrm{k}^{-1}\right.} \mathrm{TS}\right) \\
\left(\mathrm{g} \mathrm{kg}^{-1} \mathrm{TS}\right)\end{array}$ & $\begin{array}{c}\mathrm{TKN} \\
\left(\mathrm{g} \mathrm{O}_{2} \mathrm{~kg}^{-1} \mathrm{TS} \mathrm{h}^{-1}\right)\end{array}$ & $\begin{array}{c}\mathrm{AT}_{4} \\
\left(\mathrm{~g} \mathrm{O}_{2} \mathrm{~kg}^{-1} \mathrm{TS}\right)\end{array}$ \\
\hline RS & $7.1 \pm 0.1$ & $1.4 \pm 0.1$ & $325 \pm 3$ & $792 \pm 1$ & $0.2 \pm 0.1$ & $44.2 \pm 0.1$ & $4.7 \pm 0.5$ & $327 \pm 29$ \\
MSW & $6.2 \pm 0.1$ & $3.2 \pm 0.3$ & $525 \pm 38$ & $594 \pm 84$ & n.d. & $19.0 \pm 1.1$ & $2.7 \pm 0.5$ & $217 \pm 19$ \\
MSWpp & $7.3 \pm 0.1$ & $8.6 \pm 0.1$ & $462 \pm 6$ & $621 \pm 23$ & $1.4 \pm 0.1$ & $14.5 \pm 0.9$ & $2.4 \pm 0.1$ & $190 \pm 10$ \\
DS & $8.3 \pm 0.1$ & $0.7 \pm 0.1$ & $189 \pm 8$ & $628 \pm 1$ & $0.5 \pm 0.1$ & $41.9 \pm 0.9$ & $1.2 \pm 0.2$ & $82 \pm 21$ \\
OFMSWc & $8.5 \pm 0.1$ & $5.8 \pm 0.5$ & $702 \pm 5$ & $494 \pm 17$ & $4.1 \pm 0.4$ & $14.9 \pm 0.1$ & $0.4 \pm 0.1$ & $28 \pm 8$ \\
\hline
\end{tabular}


Table 2: Example of lag phase ANOVA classification for the Raw Sludge (RS) sample. Every group included values of the lag phase length (in hours) not significantly different. Values contained in a group were significantly different from the other groups.

\begin{tabular}{|c|c|c|c|c|c|c|c|c|}
\hline \multirow[t]{2}{*}{ Weeks } & \multirow[t]{2}{*}{$\mathbf{N}$} & \multicolumn{7}{|c|}{ Subset for alpha $=0.01$} \\
\hline & & Group & 1 & 2 & 3 & 4 & 5 & 6 \\
\hline 0 & 3 & & 0.32 & & & & & \\
\hline 1 & 3 & & & 13.50 & & & & \\
\hline 7 & 3 & & & 14.52 & 14.52 & & & \\
\hline 2 & 3 & & & 14.84 & 14.84 & & & \\
\hline 16 & 3 & & & 15.31 & 15.31 & & & \\
\hline 3 & 3 & & & 15.36 & 15.36 & & & \\
\hline 13 & 3 & & & 16.30 & 16.30 & 16.30 & & \\
\hline 10 & 3 & & & & 18.06 & 18.06 & & \\
\hline 44 & 3 & & & & 18.84 & 18.84 & & \\
\hline 20 & 3 & & & & & 19.92 & 19.92 & \\
\hline 36 & 3 & & & & & 20.14 & 20.14 & \\
\hline 28 & 3 & & & & & & 23.70 & 23.70 \\
\hline 52 & 3 & & & & & & & 25.51 \\
\hline Significance & & & 1 & 0.26 & 0.01 & 0.03 & 0.04 & 0.83 \\
\hline
\end{tabular}


Table 3: Summary of the effects on the organic waste samples characterized by respiration activity due to frozen storage.

RS: raw sludge; MSW: municipal solid waste; MSWpp: municipal solid waste partially processed; DS: digested sludge; OFMSWc: composted organic fraction of municipal solid waste.

\begin{tabular}{ccccc}
\hline & DRI $_{24 \mathrm{~h}}$ & $\mathrm{AT}_{4}$ & Lag phase & $\mathrm{H}_{\max }$ \\
\hline RS & No change & No change & Change from raw sample & Change from raw sample \\
MSW & Change from week 52 & Change from week 20 & Change from week 3 & Change from week 16 \\
MSWpp & No change & No change & Change from week 10 & Change from week 28 \\
DS & No change & No change & Change from raw sample & No change \\
OFMSWc & No change & No change & No change & No change \\
\hline
\end{tabular}


Figures:

Figure 1: Evolution of the respiration parameters analyzed on the organic waste samples during freezing time: a) $\mathrm{DRI}_{24 h}$; b) $\mathrm{AT}_{4}$; c) Lag phase and d) $\mathrm{H}_{\max }$.

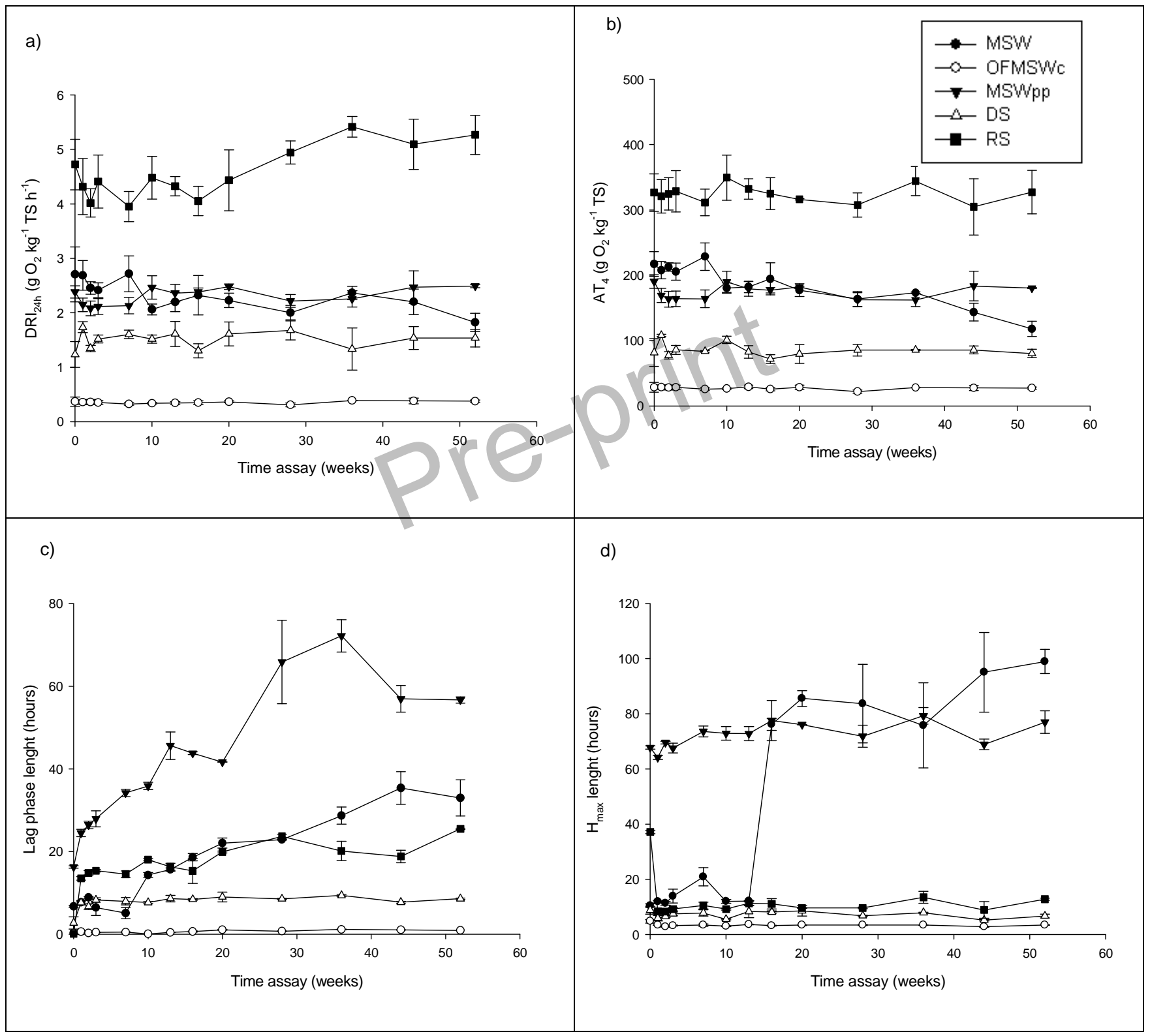

